\title{
Impedance Monitoring During Radiofrequency Catheter Ablation in Humans
}

\author{
MARK HARVEY, YOON-NYUN KIM, JOÃO SOUSA, \\ RAFEL EL-ATASSI, FRED MORADY, HUGH CALKINS, \\ and JONATHAN J. LANGBERG
}

From the Department of Internal Medicine, Division of Cardiology, The University of Michigan Medical Center, Ann Arbor, Michigan

HARVEY, M., ET AL.: Impedance Monitoring During Radiofrequency Catheter Ablation in Humans. Radiofrequency catheter ablation of accessory pathways and the atrioventricular junction often requires multiple applications of energy. The inability to determine the effects of any given application on the underlying tissue may contribute to this problem. In the present study, impedance was monitored in 20 patients undergoing radiofrequency catheter ablation, and the relationship between an initial decrease in impedance and subsequent effects were examined. An initial fall in impedance of more than $10 \Omega$ was $78 \%$ sensitive and $88 \%$ specific for predicting subsequent evidence of tissue heating (interruption of conduction or an abrupt rise in impedance due to coagulum formation). In contrast, initial values of voltage, current, or impedance did not distinguish between effective and ineffective applications of radiofrequency energy. Continuous monitoring of impedance may facilitate radiofrequency catheter ablation. (PACE, Vol. 15, January 1992)

radiofrequency catheter ablation, accessory pathways, impedance

\section{Introduction}

Catheter modification of the atrioventricular junction and ablation of extranodal accessory pathways with radiofrequency energy have been shown to be effective for definitive management of supraventricular tachycardia. ${ }^{1-4}$ Multiple applications of energy are often required to achieve a desired electrophysiological effect, increasing the duration of the procedure, the amount of radiation exposure, and the potential for complications.

Several factors, including electrode surface area,$^{5-7}$ pressure of electrode contact, ${ }^{6}$ catheter orientation, and cavitary blood flow, can affect the efficiency of tissue heating during the delivery of radiofrequency energy. Consequently, there is lit-

Address for reprints: Jonathan J. Langberg, M.D., University of Michigan Medical Center, 1500 East Medical Center Drive, B1F245, Ann Arbor, Michigan 48109-0022. Fax: (313)9367641.

Received April 22, 1991; revision July 9, 1991; accepted September $14,1991$. tle correlation between energy delivery parameters and the volume of ablative injury in vivo. ${ }^{8,9}$ The inability to determine the effects of any given radiofrequency application on the underlying tissue may contribute to the need for multiple applications.

Studies in vitro ${ }^{10,11}$ and in vivo ${ }^{12}$ have shown an early decrease in impedance due to the heating of the electrode-tissue interface, suggesting that changes in impedance might be useful for monitoring lesion formation. In the present study, impedance was monitored in 20 patients undergoing radiofrequency catheter ablation. The relationship between an initial decrease in impedance and subsequent effects was examined.

\section{Methods}

\section{Patient Population}

Twenty consecutive patients undergoing radiofrequency catheter ablation were included in this study (Table I). Ablation of the atrioventricu- 


\begin{tabular}{|c|c|c|c|c|c|}
\hline \multicolumn{6}{|c|}{$\begin{array}{l}\text { Table I. } \\
\text { and Outcome of Catheter Ablation }\end{array}$} \\
\hline Patient & Age & Sex & Diagnosis & $\begin{array}{c}\text { \# of Radiofrequency } \\
\text { Applications }\end{array}$ & Outcome \\
\hline 1 & 73 & $M$ & SVT & 2 & AV Block \\
\hline 2 & 26 & M & WPW & 25 & AP Block \\
\hline 3 & 21 & $\mathrm{~F}$ & WPW & 4 & AP Block \\
\hline 4 & 33 & $\mathrm{~F}$ & WPW & 42 & AP Block \\
\hline 5 & 47 & M & WPW & 29 & AP Block \\
\hline 6 & 26 & $\mathrm{~F}$ & WPW & 19 & AP Block \\
\hline 7 & 69 & $\mathrm{~F}$ & WPW & 3 & AP Block \\
\hline 8 & 73 & $\mathrm{~F}$ & SVT & 2 & AV Block \\
\hline 9 & 29 & $\mathrm{~F}$ & WPW & 57 & Unsuccessful \\
\hline 10 & 49 & $\mathrm{~F}$ & WPW & 23 & AP Block \\
\hline 11 & 40 & $\mathrm{~F}$ & WPW & 3 & AP Block \\
\hline 12 & 20 & $\mathrm{~F}$ & WPW & 1 & AP Block \\
\hline 13 & 35 & $M$ & WPW & 1 & AP Block \\
\hline 14 & 28 & $\mathrm{~F}$ & WPW & 3 & AP Block \\
\hline 15 & 37 & M & WPW & 1 & Unsuccessful \\
\hline 16 & 28 & $\mathrm{~F}$ & WPW & 43 & AP Block \\
\hline 17 & 49 & $\mathrm{~F}$ & WPW & 1 & AP Block \\
\hline 18 & 13 & $\mathrm{~F}$ & WPW & 29 & AP Block \\
\hline 19 & 13 & $\mathrm{~F}$ & WPW & 3 & AP Block \\
\hline 20 & 22 & M & WPW & 32 & AP Block \\
\hline
\end{tabular}

$\mathrm{AP}=$ accessory pathway; $\mathrm{AV}=$ atrioventricular; SVT $=$ supraventricular tachycardia; $\mathrm{WPW}=$ WolffParkinson-White syndrome.

lar junction was performed in two patients with drug refractory atrial fibrillation. The remaining patients had ablation of extranodal accessory pathways. The mean age was $37 \pm 18$ years, and six of the patients were men. Accessory pathways were located in the left free wall in nine, the right free wall in seven, and were septal in two patients.

\section{Catheter Ablation Procedure}

A 7 French, steerable electrode catheter with a distal electrode 4-mm in length (Mansfield Scientific, Mansfield, MA, USA) was used in all 20 procedures. Techniques for positioning the ablation catheter have been described previously. ${ }^{1,4}$ For interruption of atrioventricular conduction, the catheter was advanced across the tricuspid annulus and manipulated to record the largest His electrogram. Ablation of right free-wall and septal accessory pathways was performed by introducing the catheter into the femoral vein and positioning it at a site on the tricuspid annulus with short local atrioventricular and/or ventriculoatrial activation times. A retrograde aortic approach was used for left free-wall accessory pathways. The catheter was positioned on the ventricular side of the mitral annulus at the site of earliest activation.

Continuous, unmodulated sine wave alternating current at $350 \mathrm{kHz}$ was supplied by an electrosurgical unit (Radionics, Model RFG3B, Burlington, MA, USA). This was routed through a controller that supplied 0-1 V direct current signals corresponding to root mean squared radiofrequency voltage, current, and impedance. These were recorded along with the surface electrocardiogram on a Siemens Mingograf Model 800 (Stockholm, Sweden) strip chart recorder at a paper speed of $25 \mathrm{~mm} / \mathrm{sec}$. Calibration was performed at the beginning and end of each session. Impedance measurements were recorded at a gain of 1.5-2.0 $\Omega / \mathrm{mm}$.

All ablations were performed with the appli- 
cation of current between the distal pole of the ablation catheter and a large diameter skin electrode (Valleylab, Boulder, CO, USA) placed over the left scapula.

\section{Analysis of Data}

A decrease in impedance was defined as a decline of at least $10 \Omega$ during the initial 10 seconds of radiofrequency energy application. The $10-\Omega$ cutoff was chosen because changes of the same magnitude were seen during lesion formation in vitro. ${ }^{10}$ In addition, fluctuations in impedance during steady state were consistently $<10 \Omega$.

Since neither thermometric nor histopathological data were available in this clinical study, indirect evidence of tissue heating was used to determine the relationship between an initial fall in impedance and subsequent effects. Tissue heating was considered to have occurred if a radiofrequency application resulted in either transient or persistent interruption of the accessory pathway or atrioventricular conduction, or an abrupt rise in impedance. An impedance rise was deemed to have occurred if a value above $150 \Omega$ was recorded during the course of radiofrequency energy application. This has been shown to occur with temperatures in excess of $100^{\circ} \mathrm{C}$, which results in boiling and coagulum formation around the ablating electrode. ${ }^{11,13}$ Since lesion formation may occur in vivo without effects on conduction or coagulum formation, the criteria for tissue heating, although specific, are likely to have been insensitive.

\section{Statistical Analysis}

Results are expressed as mean \pm one standard deviation. Energy delivery parameters during applications that caused tissue heating (an electrophysiological effect or impedance rise) were compared to ineffective applications using analysis of variance. The relationship between an initial decrease in impedance and subsequent tissue heating was determined by Chi-square analysis. A P value of $<0.05$ was considered significant.

\section{Results}

Three hundred sixty-one applications of radiofrequency energy in 20 patients were analyzed.
A mean of $59 \pm 5 \mathrm{~V}$ and $0.63 \pm 0.16$ A were applied for $14 \pm 10$ seconds. The average initial impedance for the entire cohort was $98 \pm 20 \Omega$.

Evidence of tissue heating was present during $129(36 \%)$ of 361 applications of radiofrequency energy (group I). An abrupt rise in impedance occurred during 92 applications (Fig. 1A), conduction was transiently interrupted during 19 applications, and persistent ablation of the atrioventricular junction or accessory pathway occurred after 18 applications in this group.

As seen in Table II, there was no significant difference in initial voltage, current, or impedance between those applications of radiofrequency with evidence of tissue heating (group I) versus those without (group II). The duration of energy application was significantly shorter for group I than group II ( $13 \pm 8$ vs $16 \pm 12 \mathrm{sec}, \mathrm{P}=0.002)$.

An early fall in impedance occurred during 129 applications of radiofrequency energy. The mean fall in impedance was $20 \pm 10 \Omega$ over the initial $9 \pm 3$ seconds (Fig. 1B). A decrease in impedance was significantly more frequent in group I (101/129 applications) than group II (28/ 232 applications, $\mathrm{P}=0.0001$ ). An initial fall in impedance had a sensitivity of $78 \%$ and a specificity of $88 \%$ for predicting subsequent evidence of tissue heating. An initial fall in impedance occurred in $82 / 92(89 \%)$ of applications that culminated in an impedance rise, 10/20 (50\%) of applications that transiently interrupted conduction, and $9 / 18(50 \%)$ that caused persistent effects on conduction (Table III).

\section{Table II.}

Mean Radiofrequency Energy Delivery Values

\begin{tabular}{lccc}
\hline & $\begin{array}{c}\text { Group I } \\
\text { Evidence } \\
\text { of Tissue } \\
\text { Heating }\end{array}$ & $\begin{array}{c}\text { Group II } \\
\text { No Evidence } \\
\text { of Tissue } \\
\text { Heating }\end{array}$ & P \\
\hline Voltage & $58 \pm 5$ & $59 \pm 5 \mathrm{~V}$ & $\mathrm{NS}$ \\
Current & $0.64 \pm 0.15$ & $0.63 \pm 0.16 \mathrm{~A}$ & $\mathrm{NS}$ \\
Impedance & $96 \pm 21$ & $99 \pm 19 \Omega$ & $\mathrm{NS}$ \\
Duration & $16 \pm 12$ & $13 \pm 8 \mathrm{sec}$ & 0.002 \\
\hline
\end{tabular}


A.
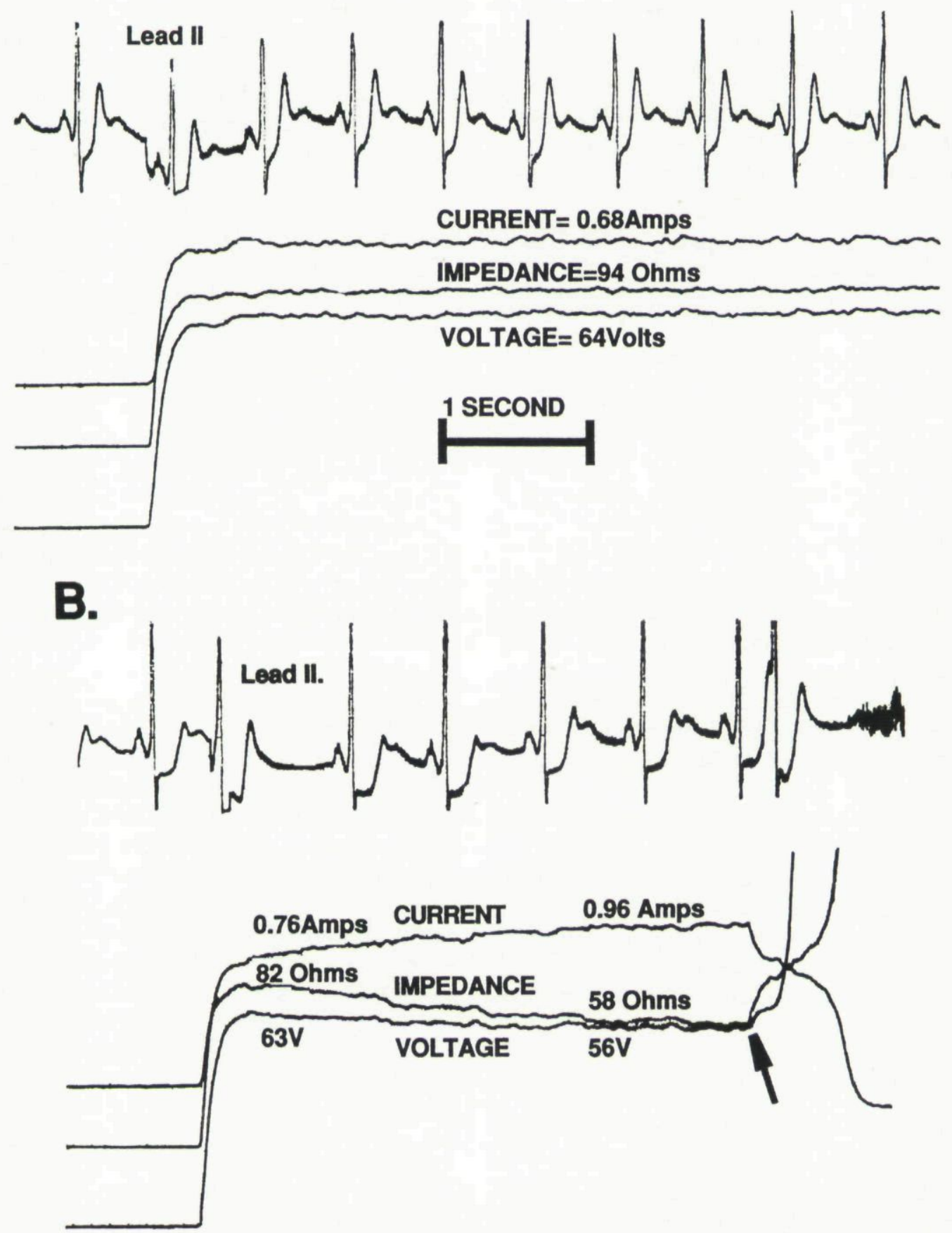

Figure 1. Monitoring of energy delivery parameters during radiofrequency catheter ablation. (A) An ineffective application-note the fact that impedance remains constant throughout the tracing. (B) An application that culminated in an abrupt rise in impedance (arrow) due to temperatures above $100^{\circ} \mathrm{C}$ at the point of contact and coagulum formation. Note that evidence of tissue heating was preceded by an early decrease in impedance from 82 to $58 \Omega$. 
Table III.

Relationship Between an Initial Fall in Impedance and Subsequent Effects

\begin{tabular}{lcr}
\hline $\begin{array}{c}\text { Effect of Radiofrequency } \\
\text { Application }\end{array}$ & $\begin{array}{c}\text { Initial } \\
\text { Fall in } \\
\text { Impedance }\end{array}$ & $\begin{array}{c}\text { No Initial } \\
\text { Fall in } \\
\text { Impedance }\end{array}$ \\
\hline $\begin{array}{l}\text { None } \\
\begin{array}{l}\text { Impedance rise due to } \\
\text { coagulum formation }\end{array}\end{array}$ & $28(12 \%)$ & $204(88 \%)$ \\
$\begin{array}{l}\text { Transient conduction } \\
\text { block }\end{array}$ & $10(50 \%)$ & $10(11 \%)$ \\
$\begin{array}{l}\text { Persistent conduction } \\
\text { block }\end{array}$ & $9(50 \%)$ & $10(50 \%)$ \\
\hline
\end{tabular}

\section{Discussion}

\section{Main Findings}

Output voltage, current and impedance were continuously monitored during radiofrequency catheter ablation in 20 patients. Initial values of these parameters were not predictive of subsequent tissue heating as manifest by an electrophysiological effect or coagulum formation. In contrast, an early fall in impedance was a sensitive and specific predictor of tissue heating.

The duration of radiofrequency energy application was larger in Group II than in Group I. This was a manifestation of the clinical protocol, since radiofrequency ablation was continued for at least 20 seconds after the onset of accessory pathway or atrioventricular block, whereas it was stopped after 15 seconds if no effects on conduction were seen.

\section{Comparison to Previous Studies}

Grogan and co-workers ${ }^{10}$ studied the changes in impedance during the course of radiofrequency lesion formation in vitro. They noted that impedance remained constant during low power application $(0.05 \mathrm{~W})$ but fell from a mean of 88-79 $\Omega$ during higher power applications of $10 \mathrm{~W}$. There was no change in impedance when $10 \mathrm{~W}$ was delivered to saline alone. These authors concluded that the monitoring of impedance during radiofrequency ablation might be useful to confirm production of tissue damage. Another study of radio- frequency lesion formation in vitro ${ }^{11}$ noted a correlation between an early rise in current flow (due to a fall in impedance) and subsequent impedance rise. In a study of endocardial radiofrequency lesion formation in dogs, Wittkampf described a $10 \%-20 \%$ decrease in impedance during the first 20 seconds of radiofrequency exposure. ${ }^{12}$

Haines and Watson ${ }^{14}$ modeled radiofrequency lesion formation as equivalent to a purely thermal source. They suggested that tip temperature monitoring would be an accurate method for prediction of the extent of ablative injury. These predictions were confirmed by Hindricks, et al., ${ }^{9}$ who showed an excellent correlation between temperature at the distal electrode and the volume of myocardial necrosis.

The initial fall in impedance described in this study is a consequence of heating at the electrodetissue interface. ${ }^{10}$ Although tip temperature monitoring would be a more direct method to assess lesion formation, thermistor-equipped catheters are not generally available for cardiac ablation. Impedance monitoring can be simply performed with any catheter and appears to have an excellent correlation with tissue heating.

\section{Limitations}

The criteria used as indirect evidence of tissue heating (effects on conduction or coagulum formation) probably underestimated the true incidence of lesion formation and therefore, the specificity of an early fall in impedance. Some of the "false positive" applications in Group II where a fall in impedance was recorded may have produced a significant lesion without culminating in coagulum formation or interruptions of conduction. A direct comparison of tip temperature and impedance changes would more accurately define the relationship between impedance and lesion formation.

High power, short duration applications of radiofrequency were used in this series of patients. The use of a different energy delivery paradigm (e.g., lower power for a longer duration) might alter the predictive accuracy of impedance monitoring.

\section{Clinical Implications}

Radiofrequency ablation is performed by first positioning the electrode catheter using fluoroscopic and electrographic information. If an initial 
application of radiofrequency energy is ineffective, a choice must be made between repeat application at the same site (usually at a higher power output) or repositioning the ablation catheter. Continuous monitoring of impedance may facilitate this decision. An early fall in impedance suggests that enough energy has been coupled to the

\section{References}

1. Calkins H, Sousa J, El-Atassi R, et al. Diagnosis and cure of paroxysmal supraventricular tachycardia or the Wolff-Parkinson-White syndrome during a single electrophysiology test. N Engl J Med 1991; 23:1612-1618

2. Goy JJ, Fromer M, Schlaepfer J, et al. Clinical efficacy of radiofrequency current in the treatment of patients with atrioventricular node reentrant tachycardia. J Am Coll Cardiol 1990; 16:418-423.

3. Langberg JJ, Chin M, Schamp DJ, et al. Ablation of the atrioventricular junction with radiofrequency energy using a new electrode catheter. Am J Cardiol 1991; 67:142-147.

4. Lee MA, Morady F, Kadish A, et al. Catheter modification of the atrioventricular junction with radiofrequency energy for control of atrioventricular nodal reentry tachycardia. Circulation 1991; 83:827-835.

5. Langberg JJ, Lee MA, Chin MC, et al. Radiofrequency catheter ablation: The effect of electrode size on lesion volume in vivo. PACE 1990; 13:1242-1248.

6. Hoyt RH, Huang SKS, Marcus FI, et al. Factors influencing trans-catheter radiofrequency ablation of the myocardium. J Appl Cardiol 1986; 1:469-486.

7. Blouin LT, Marcus FI. The effect of electrode design on the efficiency of delivery of radiofrequency energy to cardiac tissue in vitro. PACE 1989; 12:136-143.

8. Haverkamp W, Hindricks G, Gulker H, et al. Coagu- tissue to produce significant temperature elevation and that repeat applications at the same site are not likely to be effective. In contrast, a flat impedance curve may, in some cases, reflect inadequate lesion formation and prompt consideration of repeat application with higher power output and/or better tissue contact.

lation of ventricular myocardium using radiofrequency alternating current: Biophysical aspects and experimental findings. PACE 1989; 12:187-195.

9. Hindricks G, Haverkamp W, Gulker H, et al. Radiofrequency coagulation of ventricular myocardium: Improved prediction of lesion size by monitoring catheter tip temperature. Eur Heart J 1989; 20:972-984.

10. Grogan EW, Nellis SH, Subramanian R. Impedance changes during catheter ablation by radiofrequency energy: A potential method for monitoring efficacy of lesion generation. (abstract) J Am Coll Cardiol 1987; 9:95A.

11. Ring ME, Huang SKS, Gorman G, et al. Determinants of impedance rise during catheter ablation of bovine myocardium with radiofrequency energy. PACE 1989; 12:1502-1513.

12. Wittkampf FHM, Hauer RNW, Robles de Medina EO. Control of radiofrequency lesion size by power regulation. Circulation 1989; 80:962-968.

13. Haines DE, Veron AF. The impedance rise during radiofrequency ablation in vivo is prevented by maintaining an electrode tip temperature below the boiling point. Circulation 1989; 80:11-41.

14. Haines DE, Watson DD. Tissue heating during radiofrequency catheter ablation: A thermodynamic model and observations in isolated perfused and superfused canine right ventricular free wall. PACE 1989; 12:962-976. 
This document is a scanned copy of a printed document. No warranty is given about the accuracy of the copy. Users should refer to the original published version of the material. 